\title{
El retorno a la política: intento explicativo de la nueva preponderancia de la dimensión política en las relaciones internacionales
}

\author{
Daniel Bello* \\ Armando Di Filippo**
}

\begin{abstract}
Resumen: En este artículo buscamos explicar lo que llamamos "la nueva preponderancia de la dimensión política en las relaciones internacionales”, entendiendo por aquello la creciente importancia que han adquirido últimamente tanto los actores políticos como el apostar por estrategias multidimensionales en política exterior -en contraposición a estrategias unidimensionales basadas en el contractualismo económico-comercial-, para tratar de dar respuesta a las inquietantes y complejas interrogantes que presenta el actual escenario mundial.

La tesis del trabajo es que esta "vuelta a la política" en el plano internacional se explica por la confluencia de dos fenómenos-procesos: por un lado el cambio de ciclo económico - propulsado en gran parte por la crisis financiera global-, que implica el inicio de lo que el economista inglés Robert Skidelsky llama ciclo “liberal-keynesiano", y por otro lado la transformación del sistema internacional y el paso a lo que el académico estadounidense Richard Haass llama "la era de la no polaridad”.
\end{abstract}

Palabras clave: relaciones internacionales, política, ciclos económicos, sistema internacional, no polaridad.

\section{The comeback of politics: an attempt to explain the new preponderance of the political dimension in international relationships}

\begin{abstract}
In this article we seek to explain what we call 'The new preponderance of the political dimension in international relationships', and thus understand the growing importance that, not only politicians, but also multi-dimensional -in contrast to one-dimensional strategies based on the economiccommercial perspective- have recently acquired. We try to answer the worrying and complex questions that the current world stage presents.

The thesis is that this "return to politics" in the international plane is explained by the confluence of two processes: on the one hand, the change in the
\end{abstract}

\footnotetext{
* Universidad Arturo Prat, Santiago, Chile. Email: danielbello.a@gmail.com

*** Universidad Alberto Hurtado, Santiago, Chile. Email: armando.difilippo@gmail.com Agradecemos a Isaac Caro, Isabel Rodríguez y Manuel Bello, por leer y comentar las versiones preliminares del artículo.
} 
economic cycle -promoted largely by the financial global crisis- that implies the beginning of what the English economist Robert Skidelsky calls 'a liberal Keynesian cycle', and, on the other hand, the transformation of the international system and the transition to what the American academician Richard Haass calls 'the age of non-polarity'.

Key words: international relations, politics, economic cycles, international system, non polarity

\section{A volta à política: tentativa explicativo da nova preponde- rancia da dimensão política nas relações internacionais}

Resumo: Neste artigo procuramos explicar o que chamamos "a nova preponderancia da dimensão política nas relações internacionais”, entendendo por aquilo a crescente importância que adquiriram ultimamente tanto os actores políticos como o apostar por estratégias multidimensionales em política exterior -em contraposição a estratégias unidimensionales baseadas no contractualismo económico-comercial-, para tratar de dar resposta às inquietantes e complexas interrogantes que apresenta o actual palco mundial. A tese do trabalho é que esta "volta à política” no plano internacional explica-se pela confluencia de dois fenómenos-processos: por um lado a mudança de ciclo económico -propulsado em grande parte pela crise financeira global-, que implica o início do que o economista inglês Robert Skidelsky chama ciclo "liberal-keynesiano", e por outro lado a transformação do sistema internacional e o passo ao que o académico estadounidense Richard Haass chama "era-a da não polaridad”.

Palavras-chave: relações internacionais, política, ciclos económicos, sistema internacional, não polaridad

Recibido: 14.07.2009

Aceptado: 25.11.2009

$* * *$

\section{Antecedentes}

El retorno de la política a que alude este artículo puede examinarse en un contexto histórico internacional que nos remita al siglo XIX, cuando era evidente la vigencia del “dictum” de Von Clausewitz (1780-1831) según el cual la guerra era la continuación de la política por otros medios. Esta expresión, corresponde a un período de las relaciones internacionales fundadas en el así denominado realismo político que dominó durante todo dicho siglo y durante la primera mitad del siglo XX.

El realismo político exacerbó a fines del siglo XIX nuevas formas de colonialismo, y en la primera mitad del siglo XX las dos guerras más cruentas de la historia de la humanidad.

El mundo cambió en la segunda mitad del siglo XX, transicionando hacia ideales de paz, de cooperación, de defensa de derechos y libertades, de asunción de responsabilidades y reconocimiento de deberes. Estamos hablando claro está de ideales, y no de logros consolidados, pero estos ideales cristalizaron ante todo en la fundación de la Organización de las 
Naciones Unidas (ONU), en su Carta constitutiva y en el conjunto de Declaraciones que se iniciaron con la Declaración Universal de los Derechos Humanos. El proceso de descolonización por un lado y la formación del bloque soviético por el otro, configuraron los puntos cardinales del nuevo mapa político mundial: los ejes norte-sur y este-oeste. A estos impresionantes cambios en la esfera internacional, se agregó la democratización de Europa Occidental continental (Gran Bretaña y Francia habían sido, previamente, cuna de visiones alternativas de democracias liberales). A esta etapa podemos considerarla como de "transición de la política", desde un realismo basado en la violencia hacia una nueva opción de cooperación y negociación, completada con los organismos económicos intergubernamentales -Banco Mundial (BM), Organización Mundial de Comercio (OMC), Fondo Monetario Internacional (FMI) - en el marco del multilateralismo aplicado al orden capitalista internacional.

A escala nacional, el otro rasgo notable paralelo a la democratización política de Europa Occidental, fue -en la esfera socioeconómica-, la consolidación de la economía keynesiana y el surgimiento de los Estados benefactores (en sus versiones socialdemócrata o democristiana). Se generaron las economías mixtas que significaron la incorporación legítima y permanente del Estado al juego económico. Se produjo un círculo virtuoso integración-democratización-integración que terminó por generar la actual Unión Europea (UE) cuyo reclutamiento de nuevos miembros (hoy superan los veinticinco países) imponía como condición la instalación de regímenes democráticos.

Desde una perspectiva sistémica (o de juegos) durante la segunda mitad del siglo XX, los actores (jugadores) principales asumieron posiciones de poder no fundadas directamente en la fuerza (o en la amenaza de su aplicación inmediata), sino más bien en las instituciones (reglas internacionales del juego) y en las estructuras tecnológicas (reglas técnicas del juego). Fue un contexto político en que los formuladores del orden o sistema internacional (los hacedores de las reglas de juego) fueron las potencias triunfadoras de la segunda guerra mundial. Sin embargo, la sobrevivencia amenazante para las democracias liberales, de la Unión de Repúblicas Socialistas Soviéticas (URSS) contribuyó a una rápida reconstrucción de las economías de las potencias derrotadas (Italia, Alemania, Japón) y su incorporación al orden capitalista global y a los regímenes democráticos que hoy imperan en todo el mundo occidental.

La URSS como potencia políticamente alternativa, generó una situación que volvió a evocar el "dictum” de Von Clausewitz, pero esta vez en una versión “congelada” denominada “Guerra Fría”. La Guerra Fría con su equilibrio del terror atómico, recordaba a cada momento que la guerra nuclear podía ser la hirviente continuación de la política de "coexistencia pacífica”.

Con el surgimiento de las Tecnologías de la Información y Comunicación (TIC) y la caída de la URSS, ese bipolarismo potencialmente apo- 
calíptico de la Guerra Fría, no se tradujo, en lo que hubiera sido una terrible “guerra caliente” y quizá póstuma para la humanidad.

Las reglas de juego del capitalismo empezaron a preponderar sin contrapeso sobre las reglas de juego de la democracia deseada por los fundadores de la ONU a escala internacional. El juego económico internacional encontró un nuevo agente: las corporaciones transnacionales, principales beneficiarias de las reglas técnicas (TIC) e institucionales (OMC, FMI, $\mathrm{BM}$ ), de la nueva estructura del capitalismo global signada por los principios del así denominado Consenso de Washington (1989).

Comenzó, entonces, una erosión de los mecanismos políticos y de las políticas negociadas, y un incipiente retorno a las viejas prácticas violentistas del realismo político (ataque a las Torres Gemelas de Nueva York, invasión a Afganistán, e Irak). Con la excusa de instalar la democracia en naciones culturalmente ajenas a la tradición occidental se violaron las normas del derecho internacional (incluyendo las emanadas del Consejo de Seguridad). Entre otras cosas la potencia que ejercía una hegemonía unipolar tomó control de riquezas petroleras, pero a un costo político y económico enorme.

Pareció renacer, entonces la política al estilo Von Clausewitz, con su realismo político y su sabor colonialista. Pero la potencia unipolarmente hegemónica que intentó este retorno al pasado, descubrió que carecía del poderío económico para sostener el gasto de esta aventura. Sin embargo, en el intertanto (1980-2008) las reglas del juego del orden internacional se "privatizaron" a través de nuevas normas gestadas en la OMC, en el FMI (y, en menor grado, en el BM). El principal protagonista del capitalismo globalizado fue la Empresa Transnacional (ET). En nuestra analogía del juego pareció que los jugadores económicos podían crear sus propias reglas e ignorar crecientemente el sentido del multilateralismo de los organismos intergubernamentales. Tras el fracaso de las negociaciones del Acuerdo Internacional de Inversiones (AMI) (Organización Económica para la Cooperación y el Desarrollo, OECD 1995) los bancos de inversión pensaron que podían llevar al límite sus acciones microeconómicas, ignorando las antiguas recomendaciones keynesianas, independizarse de sus Estados de origen e imponerse en los países de destino de sus inversiones. El cuasi colapso del sistema financiero mundial (2008) fue una consecuencia de esa pretendida independización de las transnacionales respecto de cualquier arquitectura financiera razonable.

Hoy parecemos asistir a un retorno de las formas cooperativas y negociadas de la política internacional, gracias a ese imperfecto pero insustituible mecanismo de la democracia que reinstaló a un gobierno demócrata en EEUU.

Estamos en una situación donde, tras la negación del bipolarismo con la caída del bloque soviético, ahora parecemos entrar en una nueva negación que sería la negación del unipolarismo estadounidense. 
Por ahora no sabemos mucho más, sólo que la política de la negociación parece haber retornado para lanzar una nueva delimitación del campo de juego y de las reglas multilaterales. También sabemos que las naciones emergentes de mayor gravitación mundial tendrán una palabra importante que decir en este relanzamiento. Pero eso es todavía una expectativa. Este artículo explora las circunstancias más recientes de este retorno de la política que, esperamos, pueda reeditar el espíritu que inspiró la creación de la ONU, y no se desbarranque en el siempre latente y amenazante "dictum" de Von Clausewitz que se resiste a ser enterrado por la historia.

\section{Introducción}

“La futura política exterior de Chile deberá ser mucho más ‘política’ que 'económica', más allá de la continuidad de este rasgo, y deberá enfocarse mucho más en la región que en el resto del mundo, sin que esto implique debilitar las opciones hechas en las etapas anteriores”.

Ross (2006)

Tomando de base esta aseveración que César Ross dejara plasmada en un artículo publicado en la edición de abril-junio del 2006 de la revista Foreign Affairs En Español, y considerando que, habiendo pasado tres años desde que el artículo fuera publicado, se ha podido observar un real giro hacia "la política" como elemento preponderante de la política exterior de Chile -bajo la conducción, a partir de marzo del 2006, de la Presidenta Michelle Bachelet-, este trabajo pretende identificar cuáles son algunos de los factores que han ido -y siguen-impulsando este giro, centrando el afán explicativo básicamente en dos fenómenos de carácter estructural y global claramente interconectados: a) el paulatino paso hacia un nuevo ciclo económico "liberal-keynesiano" -en contraste con el anterior "conservadorneoclásico"-, propulsado por diversas fuerzas y dinamizado por la actual crisis financiera, y b) la transformación del sistema internacional en lo que Richard Haass (2008a) llama un sistema internacional no polar.

Desde nuestra perspectiva, ambos fenómenos-procesos generan un escenario de desafíos y complejidades, que irremediablemente demanda la búsqueda de soluciones políticas concertadas entre los diversos actores del sistema. Podríamos decir que llegamos hoy a un momento de "clímax de la incertidumbre”, en parte debido al debilitamiento de la confianza en la ortodoxia económica y la pérdida de las certezas que generaba el sistema unipolar de post Guerra Fría, que obliga a los gobiernos, especialmente aquellos que representan a Estados de rango intermedio como Chile -que se enfrentan a la "doble asimetría" descrita por Ross, y se ven afectados por el triple proceso de "difuminación del poder" (hacia arriba, hacia abajo, y hacia la dimensión representada por lo no gubernamental) (Haass 2008a)-, a concertar soluciones y a desempeñar un rol activo en la implementación de los posibles acuerdos. En este escenario, el diálogo intergubernamental, particularmente intrarregional, parece indispensable para superar los nue- 
vos desafíos y capear el temporal que se avecina en forma de recesión de la economía mundial.

Atender a la dimensión política de las relaciones entre naciones relegada a un segundo plano en los pasados largos años de fundamentalismo de mercado y “diplomacia económica”-, resulta, más que una posibilidad, una condición para afrontar el incierto panorama por venir. El éxito inicial de la Unión de Naciones Suramericanas (UNASUR) -nueva instancia de diálogo y concertación política intergubernamental de los países de América del Sur- al coordinar el trabajo conjunto y consensuado para ayudar a Bolivia a superar una reciente crisis de gobernabilidad, muestra una buena perspectiva hacia el futuro; modalidad de acción que debe servir no solo para afrontar situaciones extraordinarias (como la que se vivió en Bolivia), sino también para generar certezas y mejorar la “maniobrabilidad” y capacidad de respuesta de los gobiernos en un mundo crecientemente complejo.

\section{Breve puntualización conceptual en torno a lo que llamamos “dimensión política”}

Antes de lanzarnos al ruedo en este intento explicativo -sucinto por cierto-, es necesario dejar en claro qué estamos entendiendo por "dimensión política”.

Básicamente hacemos referencia, en forma laxa, a una idea central: la búsqueda de un “bien común” por medio del diálogo y la concertación entre Estados (gobiernos) (y en menor medida actores no estatales -organizaciones, corporaciones, etc.-), que implica traspasar los límites del simple contractualismo económico-comercial -enfocado a la apertura de mercados-, para ingresar al ámbito multidimensional de la discusión sobre el “bienestar social”, que se proyecta en aspectos tan diversos como las estrategias de desarrollo, la estabilidad político-institucional, las migraciones -y temas relacionados con los derechos y deberes ciudadanos-, la infraestructura, las crisis financieras periódicas, el calentamiento global, el terrorismo internacional, -y también- el comercio, la apertura de mercados, el movimiento de capitales, y la localización de inversiones ${ }^{1}$.

El "retorno a la política” significa, en este sentido, la ampliación de los contenidos del debate -y la acción-intergubernamental, pero en el entendimiento de que tales contenidos diversos confluyen en aquel objetivo -aparentemente- compartido de búsqueda de "bienestar” y "desarrollo social”, en un contexto de creciente importancia del rol del Estado y los agentes gubernamentales, reposicionados gracias al desgaste del modelo socioeconómico que por cerca de tres décadas constriñó el ámbito de lo

\footnotetext{
${ }^{1}$ Para una visión multidimensional del proceso de integración regional véase, entre otras fuentes Armando Di Filippo y Rolando Franco (2000) y, Rolando Franco y Armando Di Filippo (compiladores) 1999.
} 
público y orientó las políticas interiores y exteriores de los Estados hacia el aumento y consagración de los espacios (mercantiles) de libertad para los grandes actores privados. En el lenguaje de la filosofía política contemporánea, éste período implicó un alejamiento de las posiciones del igualitarismo liberal, como las postuladas por Rawls (2000) y un acercamiento a las posiciones así denominadas libertarianistas como las sostenidas por Nozick (1974). En lenguaje más generalizado y accesible, aunque menos riguroso, significó un alejamiento de las socialdemocracias de posguerra y un acercamiento a los regímenes neoliberales.

\section{Algunas implicancias del (“eterno") retorno del péndulo económico y la crisis financiera}

Según el economista inglés Robert Skidelsky (2008) -basándose en ideas del historiador Arthur Schlesinger (Goertzel 1993)-, las "modas económicas" (y políticas) transitan cíclicamente -motivadas por episodios de crisis- desde posiciones "liberales" hacia posturas "conservadoras". Las tendencias liberales -dice Skidelsky- se caracterizan por la intervención gubernamental, mientras que las conservadoras por el repliegue del gobierno y la contracción del rol desempeñado por el Estado.

A la profunda crisis de 1929, conocida como la Gran Depresión, le siguió una extensa etapa liberal signada por el New Deal del Presidente estadounidense Franklin D. Roosevelt, y las propuestas anticíclicas -de expansión del gasto público para reactivar la demanda- de John Maynard Keynes. Estas -y otras- ideas y políticas, popularizadas a escala global (dentro de los márgenes geográficos del “eje del bien” lógicamente) luego de concluida la Segunda Guerra Mundial -momento en que inicia propiamente la "era keynesiana” (Hicks 1976)-, contribuyeron a expandir el ámbito de injerencia de los actores políticos -y de "la política"-, tanto dentro como a través de los límites nacionales.

En este contexto, surge en Europa el "consenso socialdemócrata" -particularmente después de la Conferencia de Milán de 1955-, y se consolidan las ideas que dan forma al llamado Estado de bienestar, clara muestra del afán por establecer un sistema balanceado entre el accionar de los individuos, el funcionamiento de los mercados, y la "mano visible" del Estado (accionada por actores políticos coordinados) -generadora de certezas sociales y económicas-. En el plano internacional -siguiendo en Europa-, la firma del Tratado de París en 1951 estableciendo la Comunidad Europea del Carbón y el Acero (CECA) -punto de partida para la conformación de la Unión Europea- representa un claro ejemplo de la preponderancia de la "dimensión política" -tal como fue antes conceptualizada-.

En Suramérica, el ciclo liberal mostró al Estado -en general- como activo propulsor de la alicaída economía y promotor de las políticas de industrialización -necesarias en principio por las escasas importaciones de 
manufacturas a causa de la crisis mundial, y más tarde implementadas como políticas deliberadas de desarrollo-. Lentamente (el Estado) adquirió un nuevo sitial y se instaló como eje articulador de la sociedad, distribuyendo bienes y servicios, generando puestos de trabajo, regulando e interviniendo la economía, y facilitando la incorporación paulatina de actores sociales al ámbito de (incidencia sobre la) decisión política. A partir de la década del 50, ya con el sustento teórico emanado de la CEPAL (Comisión Económica para América Latina y el Caribe de las Naciones Unidas), el Estado asume un rol consciente en la travesía al desarrollo, que a la postre lleva a los gobiernos a ensayar alianzas regionales tendientes a ampliar mercados para viabilizar las estrategias (desarrollistas) de Industrialización por Sustitución de Importaciones (ISI). El Acuerdo de Cartagena de 1969, por medio del cual se da origen al Pacto Andino, es un buen ejemplo de aquello, y es también -al igual que el Tratado de París- un ejemplo nítido de lo que se interpreta (en este escrito) como "primacía de la política”-comprobable al menos en el plano discursivo-.

La elevada inflación de los años 1970, producto de las políticas keynesianas de búsqueda del pleno empleo mediante la expansión del gasto público -en la incendiaria retórica de Milton Friedman (apologista del "libre mercado")-, condujo a un nuevo ciclo conservador. El modelo económico instaurado en gran parte del mundo desde mediados de la década del 1970 y con mayor fuerza en los 80`s - a partir de la llamada Revolución Conservadora-, se caracterizó, en términos generales, por el papel central concedido a los actores privados, y al mecanismo de mercado (autorregulado por la acción racional de los individuos), visto como único medio "eficiente” de distribución de recursos y factores. Sustentado en ideas abstractas y teorías “autistas”-neo-clásicas-, patológicamente desconectadas de la realidad social, este modelo -así llamado “neoliberal”- encontró en el Estado al culpable de todos los males, y en el libre actuar de los individuos -al son de las naturalizadas reglas de la oferta y la demanda- el camino hacia la “resolución de los grandes problemas de la humanidad” (Beck 2001).

Al ser acogidos acríticamente por un elevado porcentaje de gobiernos alrededor del planeta -o impuestos por las presiones de inquietos acreedores-, tales planteamientos generales produjeron la preeminencia -y expansión a todos los ámbitos sociales- de una visión economicista dogmática, que provocó - gracias a las privatizaciones, la liberalización y desregulación de los mercados- la jibarización del Estado, la reducción del ámbito de lo público, y la contracción de las capacidades de maniobra de los actores políticos. En tal escenario, los agentes privados (individuos y organizaciones) adquirieron particular importancia, tanto a nivel intranacional como internacional, asumiendo funciones antes monopolizadas por el Estado (como la prestación de servicios básicos), encabezando los procesos nacionales de inserción económica en las redes de flujos globales, y conduciendo los procesos de “desarrollo” (mal entendidos como de crecimiento del PIB).

Considerando aquello, no es de extrañar que durante esta etapa “con- 
servadora" algunos de los acuerdos de integración nacidos bajo el signo del ciclo anterior -como el Mercado Común Centroamericano (1960) y el Pacto Andino (1969) - hayan sido "relanzados", es decir reformulados, dejando de lado casi todo lo que en ellos había de "político", y rescatando los aspectos puramente comerciales (Gudynas 2005). En palabras de Eduardo Gudynas (2005), siguiendo los planteamientos de la "nueva” CEPAL -adaptada a los nuevos tiempos- se adoptó una “... visión 'contractual' de la integración, donde los gobiernos intercambian concesiones comerciales, con una institucionalidad mínima” (p. 9). Esto es, "política exterior sin política" (foreign policy without politics, para que se entienda). Nada más claro en este sentido que los Tratados de Libre Comercio (TLC) promovidos por EEUU.

Skidelsky escribió en septiembre del año 2008 que: “... la bancarrota amenazadora de Lehman Brothers y la venta forzada de Merrill Lynch, dos de los nombres más importantes del mundo de las finanzas, marcan el fin de una era". Hoy, dada la cantidad (y cualidad) de "agua transcurrida bajo el puente" en estos meses, parece cierto que ese fin implica el comienzo de un nuevo ciclo liberal.

El monumental desastre financiero de la actualidad (relacionado con los destinos de Lehman Brothers y Merrill Lynch), que empezó a hacerse evidente con la crisis de las hipotecas subprime en junio del 2007, muestra las falencias del modelo económico que se implantó décadas atrás -con la aparición de los "revolucionarios conservadores”-, y que prometía transmutar - por decir de alguna manera- un acto de fe (la confianza ciega en el libre mercado) en desarrollo y "felicidad" (en sentido utilitarista).

En contraste con lo prometido, pudimos ver -en estos meses de crisis- que el dogma que predicaba sobre la capacidad de autorregulación de los mercados resultó ser puro "misterio" y profecía incumplida; vimos como la economía sin política, es decir el mercado sin Estado -idea central del programa conservador-, posibilitó el descontrol de las ambiciones, la corrupción en la medición de riesgos, la especulación desmedida, la alocada "innovación" financiera, el crecimiento -y explosión- de una "burbuja inmobiliaria”, y el consecuente descalabro económico del que somos testigos.

El presente escenario, que partió siendo de crisis financiera y se convirtió en uno de recesión económica -es decir de decrecimiento de la economía "real"-, ha obligado a los gobiernos de Estados Unidos y de varios países de Europa a intervenir los mercados crediticios -inyectando liquidez al sistema-, y a nacionalizar buena parte de la banca hipotecaria y financiera que se encontraba al borde del colapso, intentando así evitar la parálisis total de la economía global. Ha obligado -además- a estos gobiernos, y a otros tantos del mundo en desarrollo, a planificar (¡sí, planificar dejó de ser un tabú!), acciones estratégicas de corte keynesiano, destinadas a reactivar la economía por medio de una gigantesca inversión pública en obras de distinto tipo, destinadas a generar empleo para, en definitiva, 
incentivar la demanda y estimular la producción².

Todo lo anterior señala el cambio hacia una nueva etapa (liberalkeynesiana) de primacía del Estado, de preeminencia de los actores políticos, y de preponderancia de la política -por sobre la economía- como medio para buscar y encontrar soluciones a las acuciantes dificultades actuales y por venir. Parece ser que estos cambios -al igual que antes- se verán reflejados -como de hecho ya se van viendo- tanto a nivel interno, en la política doméstica, como a nivel internacional (en la política exterior). En este sentido, no es de extrañar la importancia -simbólica más que factualque adquirió la reciente reunión del $\mathrm{G} 20(+2)^{3}$, de donde emergieron los primeros atisbos de una respuesta conjunta a la crisis económica; también es destacable el éxito de la reunión de presidentes de los países de la UNASUR -en Santiago de Chile (septiembre del 2008)-, de la cual surgió una firme declaración consensuada de apoyo al gobierno boliviano -que atravesaba por serios problemas de estabilidad institucional-, en la que -además del apoyo verbal-se anunció la conformación de dos Comisiones -que hoy exhiben importantes logros-, para acompañar los diálogos entre el gobierno y la oposición, y para investigar los hechos de violencia acaecidos en el norteño departamento de Pando.

En un plano más bien doméstico, podemos indicar a las nacionalizaciones de las gigantes hipotecarias estadounidenses Fannie Mae y Freddie Mac, y del banco británico Northern Rock, como signos claros de esta nueva era en que las decisiones políticas prevalecen por sobre el dogma economicista conservador. Lo mismo podríamos decir de la nacionalización en Argentina de los fondos de pensiones, manejados durante buena parte del ciclo conservador-neoclásico por las privadas Administradoras de Fondos de Jubilaciones y Pensiones (AFJP). Todas estas, acciones absolutamente impensables hasta hace muy poco tiempo.

Quedan por ver las reales implicancias futuras del ciclo económico/ político que -en términos teóricos- recién inicia, pero no así en términos prácticos. Hay que considerar que los procesos de cambio son paulatinos, y que lo que hoy marcamos como un hito no es otra cosa que el punto cúlmine en un camino de transformaciones que comenzó tiempo atrás. Ya en el 2001, Ulrich Beck pronosticaba el "fin del neoliberalismo" como resultado -en parte- de la "lógica" incompatibilidad entre el raciocinio económico de los agentes privados y el interés público, incongruencia que se hizo trágicamente evidente con los atentados terroristas del 11 de septiembre (del 2001), al dejar al descubierto la insolvencia y debilidad de la privatizada -y probablemente muy "eficiente" (es decir rentable) - seguridad aérea de Estados Unidos. Obviamente, esta catástrofe ocasionó grietas en los cimientos de la "fe".

\footnotetext{
${ }^{2}$ Esto en contra del dogma pero con el apoyo y decisión de los más importantes "guardianes de la fe” (como Henry Paulson, Ben Bernanke y George W. Bush por citar a algunos).

${ }^{3}$ Grupo de los países más industrializados y las economías emergentes más importantes del planeta (G-20), incluyendo a España y Holanda (+2).
} 
En Latinoamérica, los magros resultados obtenidos durante la era "neoliberal” (ciclo conservador) fueron provocando -en palabras de Carlos Pérez Llana (2007)- "la inversión de los paradigmas y el retorno a 'primero lo político'”. El incremento de las brechas sociales y la sensación generalizada de que los beneficios se concentraron en un porcentaje muy menor de la población -históricamente favorecida- en algunos casos propulsó la caída de regímenes políticos, y en otros obligó a los gobiernos a "hacerse cargo de políticas públicas activas y de contención social” (Pérez Llana 2007). Desde fines del siglo pasado hemos visto un cambio importante en los liderazgos políticos en la región, en particular con la entrada al ruedo de actores contrarios al dogma económico (o no tan comprometidos con él), que han venido impulsando -para bien o para mal-agendas centradas en repotenciar el rol del Estado, expandir el ámbito de lo público-político, y fortalecer -o crear-foros de discusión y concertación intergubernamental.

Como dijo Ulrich Beck (2001), “en un mundo de riesgos globales (y de injusticias sociales agregaríamos nosotros), la consigna del neoliberalismo, que llama a reemplazar la política y el Estado por la economía, se vuelve cada vez menos convincente”.

\section{El sistema internacional y las consecuencias del paso a la "era de la no polaridad"}

En paralelo al vaivén pendular de las modas económicas (y políticas) -aunque no en completa sincronía con ellas-, el orden mundial, a lo largo del siglo XX y lo que va del XXI, sufrió importantes transformaciones relacionadas con la repartición del poder, y la disputa por la ocupación de la posición hegemónica en el sistema internacional.

La primera mitad del siglo pasado estuvo caracterizada por una cierta distribución equitativa de fuerzas entre un grupo de potencias estatales (o imperiales) medianamente homogéneas, que conformaron lo que se conoce como un sistema internacional multipolar -esto es con "varios polos o concentraciones diferenciadas de poder” (Haass 2008a:66)-. Esta configuración -como sabemos- resultó bastante inestable a la luz de las dos conflagraciones mundiales que prácticamente destruyeron Europa -y buena parte del mundo-. Luego del periodo particularmente violento signado por las guerras -entre 1914 cuando inicia la Primera Guerra Mundial, y 1945 cuando culmina la Segunda-, el sistema experimentó una importante mutación producto del desgaste y deterioro de algunas de las potencias que hasta entonces habían compartido la supremacía internacional. De las ruinas de Europa (y de China, Japón, etc.) emergió un nuevo orden en el que la posición hegemónica quedó en manos de los dos Estados que lograron -excepcionalmente- prevalecer relativamente incólumes al desastre, Estados Unidos y la Unión Soviética. Se estableció así un sistema bipolar, en el que los grandes actores ejercieron absoluta primacía sobre el resto, y se dividieron el mundo en zonas de influencia que quedaron -luego de una etapa de "fo- 
gosa” conflictividad- consolidadas, propiciando la tensa calma característica de las postrimerías de la llamada Guerra Fría. Con el desplome del bloque soviético -suceso que se podría situar históricamente entre el inicio de la Perestroika (reformas impulsadas en la URSS. por el presidente Gorbachov) en 1985, y la disolución de la Unión Soviética en 1991, pasando por la célebre y simbólica caída del Muro de Berlín en 1989-, la única potencia que quedó en pie con el suficiente poder como para arrogarse la hegemonía del sistema internacional fue Estados Unidos. A razón de esta clara supremacía se constituyó el esquema unipolar que hasta hace poco tiempo reflejó las posiciones de fuerza en el tablero mundial.

En la actualidad, a pesar de que Estados Unidos continúa siendo la principal potencia del orbe -lo que nos hace pensar en la persistencia del sistema unipolar-, y que la actividad económica mundial se concentra -en un $80 \%$ - en un puñado de países o bloques (China, Estados Unidos, India, Japón, Rusia y la Unión Europea (Haass 2008a)) -cosa que podría significar el retorno a la multipolaridad-, lo que en realidad estamos presenciando es un nuevo tipo de configuración internacional que Richard Haass (2008a, 2008b) denomina “no polar”. A decir de Haass (2008b) “el mundo actual no está dominado por una o dos o incluso varias potencias, sino que recibe las influencias de decenas de protagonistas estatales y no estatales que ejercen diversos tipos de poder”. Este nuevo escenario sería el resultado de la conjugación de tres factores y procesos: en primer lugar, el crecimiento económico de algunos Estados les ha conferido mayor poder y por tanto les ha permitido mejorar su posición relativa en el sistema; en segundo lugar, la mundialización ha ido mermando el protagonismo del Estado como actor -antes exclusivo- del sistema internacional, confiriendo roles de creciente importancia -y por ende poder- a otras entidades. Esto está relacionado con lo que ya en la introducción llamamos el "triple proceso de difuminación del poder”. Hacia arriba (el poder) se dirige a las instancias y organismos supranacionales e internacionales; hacia abajo, a las instancias subnacionales como estados, regiones, departamentos o ciudades; y hacia el costado, a una gran diversidad de organizaciones no gubernamentales (ONG) y corporaciones. Finalmente en tercer lugar - volviendo a los factores causantes del presente contexto-, la política exterior de Estados Unidos le ha ocasionado al país del norte una pérdida de poder relativo frente al resto de actores del sistema. En consecuencia, lo que hoy vemos es una inédita distribución de fuerzas entre una amplia gama de actores de distinto tipo, que -a todas luces- complejiza y siembra dudas sobre el panorama general del sistema internacional.

Mal que mal, los balances de poder del esquema bipolar de la Guerra Fría permitieron que cada actor conociera con certeza y claridad a los interlocutores (copartícipes del sistema) y sus fortalezas y debilidades relativas, facilitando las tareas de coordinación y diálogo entre algunos, y de vigilancia y búsqueda de contrapesos entre otros, lo que posibilitó sellar importantes acuerdos, como los ya famosos de Bretton Woods en 1944 que dieron un marco institucional al orden (occidental) emergente- (y los antes mencionados tratados de París y Cartagena), e impidió que los 
enfrentamientos entre los dos grandes antagonistas llegaran a niveles inmanejables y desastrosos. En tanto, el (des)balance de poder propio del sistema unipolar de post-Guerra Fría, generó ciertas certezas sobre cuáles eran las reglas de juego válidas (libre mercado, democracia formal, etc.), quiénes los jugadores preponderantes, y quién el "hegemón” y único rule maker (hacedor de reglas) capaz de modificar -casi- a voluntad las estructuras institucionales del orden imperante. Con el desplome de los socialismos reales, y la proclamación de "el fin de la historia” (Fukuyama 1989), pareció que el esquema unipolar iba camino a consolidarse, junto con un pensamiento único, incuestionable, irrebatible y dogmático, sustentado en las aparentes ventajas del libre mercado global (desregulado), la acción racional del homo economicus -el individuo maximizador-, el Estado mínimo, la política precaria y la economía (“friedmaniana”) a todo evento. Con la unipolaridad se llegó al punto álgido del ciclo conservador, se extendió el dogma al mundo, y se aceptaron las certezas (espurias) y los ordenamientos del nuevo credo -y de la nueva configuración sistémicasin miramientos. Pero, lejos de consolidarse y prolongarse adt eternum, el sistema unipolar -y con él el ciclo conservador- hizo (y está haciendo) agua, dejando más preguntas que respuestas, incertidumbres, y un paisaje internacional -como vimos- altamente complejo.

En contraste con los esquemas precedentes, el sistema no polar brinda pocas certezas y parece poseer una orientación al caos. La proliferación de actores estatales y no estatales entorpece la identificación de interlocutores; "la existencia de más encargados de adoptar decisiones dificulta que las decisiones se adopten" (Haass 2008b); las reglas de juego ya no son incuestionablemente válidas para todos; la complejidad de la sociedad mundial genera nuevos mecanismos para regular las relaciones entre privados (sin la participación estatal) -como el régimen jurídico neoespontáneo (Mascareño 2007)-, abriendo un espacio para eventuales descoordinaciones o resoluciones contrapuestas (entre los distintos niveles de regímenes jurídicos ${ }^{4}$ ); y "la falta de polaridad aumenta también el número y la gravedad potencial de las amenazas, ya sean Estados delincuentes, grupos terroristas o milicias” (Haass 2008b).

En este confuso escenario -que se vislumbra como progresivamente caótico-, redoblar los esfuerzos por encontrar respuestas conjuntas y coordinadas a los problemas globales entre la amplia gama de actores -antigua y recientemente- “empoderados”, resulta más que una opción una necesidad. Un multilateralismo ajustado a las nuevas condiciones globales y sistémicas aparece como requisito para hacer frente a la realidad de latente conflictividad del “orden” no polar. Tal cosa implica un gran compromiso por parte de los agentes políticos, especialmente de aquellos (aun) más

\footnotetext{
${ }^{4}$ Un ejemplo en este sentido -quizá banal pero que da luces sobre posibles “desencuentros" futuros entre distintos niveles de regímenes jurídicos- es el pasado conflicto entre el Estado peruano y la Federación Internacional de Futbol Asociado (FIFA), que mantuvo al Perú suspendido de toda actividad futbolística internacional.
} 
poderosos, para crear (o reformular) instancias y foros de discusión y decisión internacional que den cuenta del multicromático y polifacético cuadro mundial, incluyendo en el debate a actores antes excluidos y relegados ${ }^{5}$. A este respecto creemos que cabe volver a señalar a la pasada reunión del G20 (+2) en Londres (abril del 2009), como un ejemplo de la importancia actual de buscar acuerdos entre un núcleo ampliado de actores relevantes, en aquel caso conformado por los ocho países más industrializados del planeta, las once economías emergentes más importantes, la Unión Europea como bloque, y España y Holanda.

“La no polaridad será difícil y peligrosa; sin embargo, fomentar un mayor grado de integración global ayudará a promover la estabilidad. Constituir un grupo central de gobiernos y terceros comprometidos con un multilateralismo cooperativo sería un gran avance. Llamémosle "no polaridad concertada”; esta no eliminaría la no polaridad, pero ayudaría a manejarla y disminuiría la probabilidad de que el sistema internacional se deteriore o se desintegre” .

Haass (2008a:77).

Lo anterior vale por decir que la política es (se ha vuelto) indispensable para afrontar las vicisitudes -presentes y futuras- de este (nuevo) mundo plagado de incertezas, en constante cambio y paulatina complejización. En tal sentido es que creemos pertinente aseverar que el paso a la era de la no polaridad propulsa -al igual que el cambio de ciclo económico-, en alguna medida importante el "retorno a la política", especialmente en el marco de las relaciones internacionales.

Este retorno a la política es también un retorno a la discusión de los temas éticos que subyacen tras objetivos genéricos tales como el bienestar social o el bien común, y un distanciamiento respecto de la ética y la epistemología recalcitrantemente individualistas inherentes al período neoliberal. Una señal significativa en esa dirección la dio el Papa Benedicto XVI, en su encíclica Caritas in Veritate, con su llamado a establecer una autoridad mundial localizada en la ONU, que, bajo los principios del estado de derecho y la subsidiariedad política, regule las fuerzas transnacionales del capitalismo global que siguen amenazando la estabilidad económica y política del orden mundial.

\section{A modo de conclusión}

Hemos tratado -en estas páginas- de mostrar algunos de los factores y procesos que se pueden interpretar - a nuestro juicio- como causales

\footnotetext{
${ }^{5}$ En este sentido, modificar las instancias internacionales ya existentes -como el Consejo de Seguridad de las Naciones Unidas- para que sean un reflejo del actual sistema internacional y no del esquema de la Guerra Fría sería un importante avance.
} 
de lo que en el título llamamos "el retorno a la política” y "la nueva preponderancia de la dimensión política en las relaciones internacionales”.

Siguiendo la argumentación esgrimida, podemos afirmar que tanto el retorno del péndulo de los ciclos económicos - consecuente del progresivo deterioro y reciente colapso del modelo conservador-neoclásico-, como el paso a la era de la no polaridad -marcado por la reconfiguración del sistema internacional y la redistribución del poder entre un número extenso de actores diversos-, generaron y generan un escenario de incertidumbres y complejidades que -como dijimos antes- suscita inexorablemente la búsqueda de soluciones políticas concertadas entre los diferentes actores del sistema.

Ante las patentes falencias del modelo económico del ciclo precedente (conservador-neoclásico), y el sismo provocado por la actual crisis financiera, cuyos resultados profundos aun están por verse, el Estado -único ente capaz de invertir (expandir el gasto) para incentivar la demanda- reasume (reasumió y reasumirá) un rol protagónico en la conducción de la economía, permitiendo -en buena medida- que se reabran los espacios de libertad para el accionar de los agentes políticos, y posibilitando que la política vuelva a ejercer primacía -por sobre la estrecha lógica economicista- en la agenda nacional e internacional. Así, el paso hacia un nuevo ciclo liberal-keynesiano, que responde a la necesidad de resolver los problemas -estructurales (pasados y presentes) y coyunturales (actuales)- legados del ciclo conservador, implica un -axiomático"retorno a la política".

En tanto, la transformación del sistema internacional en un esquema no polar -de distribución difusa del poder-, plantea complejos desafíos y siembra dudas, que obligan a redoblar esfuerzos por encontrar respuestas a través del diálogo y la concertación entre una ampliada gama de actores, lo que redunda en una "nueva preponderancia de la dimensión política en las relaciones internacionales”.

La política exterior de Chile parece estar hoy orientada por estas “fuerzas", mostrando una clara inclinación hacia la dimensión política como fórmula estratégica de búsqueda de soluciones y respuestas para enfrentar viejos y nuevos problemas. Sin querer profundizar mucho en este asunto, debido a que -como se desprende del razonamiento precedente- la cita inicial a Ross y la mención a la particularidad del caso chileno (en la introducción) básicamente sirvieron de pretexto para desarrollar un planteamiento de carácter general, vale la pena señalar tres hitos que permiten verificar la actual orientación de Chile hacia la política en el ámbito de las relaciones internacionales: el inédito nivel de diálogo y confianza con Bolivia, que se expresa en la agenda sin exclusiones para tratar temas de futuro sin olvidar las problemáticas del pasado; la profundización de las relaciones con Argentina, puesta en evidencia -por ejemplo- con la creación de la Fuerza de Paz Combinada "Cruz del Sur" para la actuación conjunta en operativos de paz de las Naciones Unidas; y la activa participación -y el rol protagónico- 
del gobierno de Chile en el desarrollo -y hasta ahora positivo desempeñode la Unión de Naciones Suramericanas.

Tales ejemplos, junto con otros presentados a lo largo de estas páginas, revelan la primacía de la política -tal como se entiende en este texto-, y marcan una etapa que se abre de propensión al diálogo y al entendimiento en la búsqueda de respuestas a nuevas y añejas interrogantes. 


\section{Bibliografía}

Beck, Ulrich (2001), “El fin del neoliberalismo”. El País.com. Revisado en septiembre de 2008. (http://www.elpais.com/articulo/opinion/fin/ neoliberalismo/elpepiopi/20011115elpepiopi_8/Tes).

Benedicto XVI (2009), Encíclica Caritas in Veritate.

Bresser-Pereira, Luiz Carlos (2008), “A volta da política”. Bresser-Pereira website. Revisado en octubre de 2008. (www.bresserpereira.org.br).

Di Filippo y Franco (2000), Integración Regional, Desarrollo y Equidad, SigloXXI y CEPAL/ONU, ISBN 968-23-2215-4

Franco y Di Filippo (1999), Compiladores, Las dimensiones sociales de la integración regional en América Latina, CEPAL, Naciones Unidas, Número de venta S.99.II.G.6, ISBN 92-1-321489-3.

Goertzel, Ted (1993), “Ciclos en la psicología de masas de la conducta electoral americana”. Psicología y Política. $N^{\circ} 7$ 63-84.

Haass, Richard (2008a), "La era de la no polaridad”. Foreign Affairs Latinoamérica Volumen 8. Número 3. Revisado en octubre de 2008. (http:/ /fal.itam.mx/FAE/?p=30).

Idem (2008b), "Vivir en un mundo no polarizado”. Project Syndicate. Revisado en septiembre de 2008. (http://www.project-syndicate.org/ commentary/haass21/Spanish).

Hicks, John (1976), La crisis de la economía keynesiana, Editorial Labor, Barcelona.

Krugman, Paul (2008), “El miedo y el lento deterioro”. New York Times Syndicate. Revisado en agosto de 2008. (www.nytsyn.com).

Idem (2008), “La hora de la verdad”. New York Times. Revisado en octubre de 2008 (www.nytimes.com).

Idem (2008), “¿Quién era Milton Friedman? El País (España). Revisado en octubre de 2008. (www.elpais.com).

Mascareño, Aldo (2007), "Regímenes jurídicos en la constitución de la sociedad mundial”. Política Criminal. $N^{\circ} 4$ 1-39.

Nozick Robert (1974), Anarchy, State and Utopia, Oxford, Blackwell.

Pérez Llana, Carlos (2007), “Modelos políticos internos y política exterior en América Latina”. Foreign Affairs en español. Revisado en septiembre de 2008. (www.foreignaffairs-esp.org/20071001faenespessay070404/ 
Polis, Revista de la Universidad Bolivariana, Volumen 9, $N^{\circ}$ 25, 2010

carlos-perez-llana/modelos-politicos-internos-y-politica-exterior-enamerica-latina.html)

Rawls John (2000), Teoría de la Justicia, Fondo de Cultura Económica, México.

Ross, César (2006), “Chile: los desafíos de la política exterior de Michelle Bachelet”. Foreign Affairs en español. Abril-Junio.

Skidelsky, Robert (2008), “Adiós a la revolución neoclásica”. Project Syndicate. Revisado en septiembre de 2008. (www.projectsyndicate.org/ commentary/skidelsky9/Spanish). 